\title{
Thymic carcinoma associated with Sjögren's syndrome and syndrome of inappropriate antidiuretic hormone
}

\author{
Chin-Chih Chang, MD, ${ }^{\mathrm{a}}$ Yih-Leong Chang, $\mathrm{MD},{ }^{\mathrm{b}}$ and Yung-Chie Lee, $\mathrm{MD}, \mathrm{PhD},{ }^{\mathrm{a}}$ Taipei, Taiwan
}

Thymomas are thymic epithelial tumors. The term thymoma has been customarily restricted to those neoplasms arising from or exhibiting differentiation toward thymic epithelial cells. ${ }^{1}$ Thymomas with capsular or extracapsular invasion were thought to be malignant thymomas. Thymic carcinoma was defined as a malignant epithelial tumor with overt cytologic atypia and without organotypic features. ${ }^{1}$ Thymic carcinoma is rare and accounts for $0.06 \%$ of all thymic tumors. ${ }^{2}$ Thymoma is frequently associated with parathymic autoimmune diseases. In contrast, the association of thymic carcinoma and autoimmune disease is rare. ${ }^{3}$ We present an interesting case of thymic carcinoma associated with 2 rare parathymic syndromes.

\section{CLINICAL SUMMARY}

A 66-year-old woman complained of dry mouth and dry eyes for 3 months. In addition, intermittent chest tightness and weakness of bilateral legs were also noted for 2 months. She had no ptosis, diplopia, or claudication but had the equivocal symptom of fluctuation. On physical examination, Raynaud's phenomenon was noted. Muscle power and deep tendon reflex were within normal limits.

Schirmer's test results for the patient were $4 \mathrm{~mm}$ in the right eye and $3 \mathrm{~mm}$ in the left eye. Serologic examination demonstrated that the antinuclear antibody was weakly positive (1:80 with a nucleolar pattern). The antibodies to SS-A and SS-B were negative. C3 and C4 were within normal range. The antiacetylcholine receptor antibody levels was $0.41 \mathrm{nmol} / \mathrm{L}$ (normal range, approximately $0.2-0.5 \mathrm{nmol} /$ L). Use of sialoscintigraphy revealed accumulatory and excretory dysfunction at bilateral parotid glands. Electromyographic analysis showed some neurogenic polyphasic waves, suggesting a polyradiculopathy involving bilateral lumbosacral roots. Spinal magnetic resonance imaging demonstrated early change of herniation of intervertebral discs at multiple levels of the lumbar spine. According to the latest classification criteria for Sjögren's syndrome

\footnotetext{
From the Departments of Surgery, ${ }^{\mathrm{a}}$ and Pathology, ${ }^{\mathrm{b}}$ National Taiwan University Hospital and National Taiwan University College of Medicine, Taipei, Taiwan. Disclosures: None.

Received for publication April 7, 2008; revisions received April 24, 2008; accepted for publication May 6, 2008; available ahead of print Sept 1, 2008.

Address for reprints: Yung-Chie Lee, MD, PhD, Department of Surgery, National Taiwan University Hospital, No. 7, Chung-Shan South Rd, Taipei 100, Taiwan (E-mail: yclee@ntuh.gov.tw).

J Thorac Cardiovasc Surg 2010;139:e1-2 0022-5223/\$36.00

Crown Copyright (C) 2010 Published by Elsevier Inc. on behalf of The American Association for Thoracic Surgery

doi:10.1016/j.jtcvs.2008.05.044
}

proposed by the American-European Consensus Group in 2002, the patient fulfilled 4 of the 6 criteria items listed as follows: criterion I, ocular symptoms; criterion II, oral symptoms; criterion III, ocular signs; and criterion V, salivary gland involvement. As a result, the patient satisfied the diagnostic criteria of Sjögren's syndrome.

In addition, she was found to have hyponatremia (118 $\mathrm{mmol} / \mathrm{L})$. Syndrome of inappropriate antidiuretic hormone (SIADH) was suspected based on high urine osmolarity (494 mOsm $/ \mathrm{kg}$ ); high urine sodium concentration (54 $\mathrm{mmol} / \mathrm{L})$; normal renal, adrenal, and thyroid function; and relatively low blood urea nitrogen $(7.8 \mathrm{mg} / \mathrm{dL})$ and uric acid $(4.1 \mathrm{mg} / \mathrm{dL})$ levels. The problem of hyponatremia was refractory to the treatment of water restriction. The results of chest radiographic analysis were unremarkable (Figure 1, A). However, chest computed tomographic scanning was arranged to exclude underlying pulmonary diseases or tumors associated with SIADH and revealed a lobulated thymic mass of $2.4 \mathrm{~cm}$ in size in the anterior mediastinum (Figure 1, B).

Video-assisted thoracoscopic radical thymothymectomy was performed. There was a lobulated, elastic, firm, noncapsulated mass in the thymus, measuring $5.5 \times 5.0 \times 1.5 \mathrm{~cm}$ in size. Microscopically, nests of squamous carcinomatous cells and prominent lymphoid follicles with germinal center formation were noted (Figure 2, A). These findings were different from the classical presentation of fibrous stroma in thymic cancer. Thymic carcinoma was confirmed by means of immunohistochemical staining, showing that the carcinomatous cells were immunoreactive to cytokeratin and CD5 (Figure 2, B). Hence the diagnosis of the secondary Sjögren's syndrome associated with thymic carcinoma was also made.

The postoperative course was uneventful. The patient underwent adjuvant radiation therapy with a total dose of 54 Gy divided in 30 fractions. At the 5-month follow-up, the patient completely recovered from hyponatremia, and the serum sodium concentration was $141 \mathrm{mmol} / \mathrm{L}$. The symptom of dry eyes and mouth improved slightly. Whole-body positron emission tomographic analysis 9 months after the operation showed no evidence of tumor recurrence.

\section{DISCUSSION}

Sjögren's syndrome is a chronic autoimmune disease characterized by lymphocytic infiltration of the exocrine glands resulting in xerostomia and xerophthalmia. It is rarely associated with thymoma. ${ }^{4}$ Only 1 case of thymic carcinoma associated with Sjögren's syndrome has been reported. ${ }^{3}$ The 

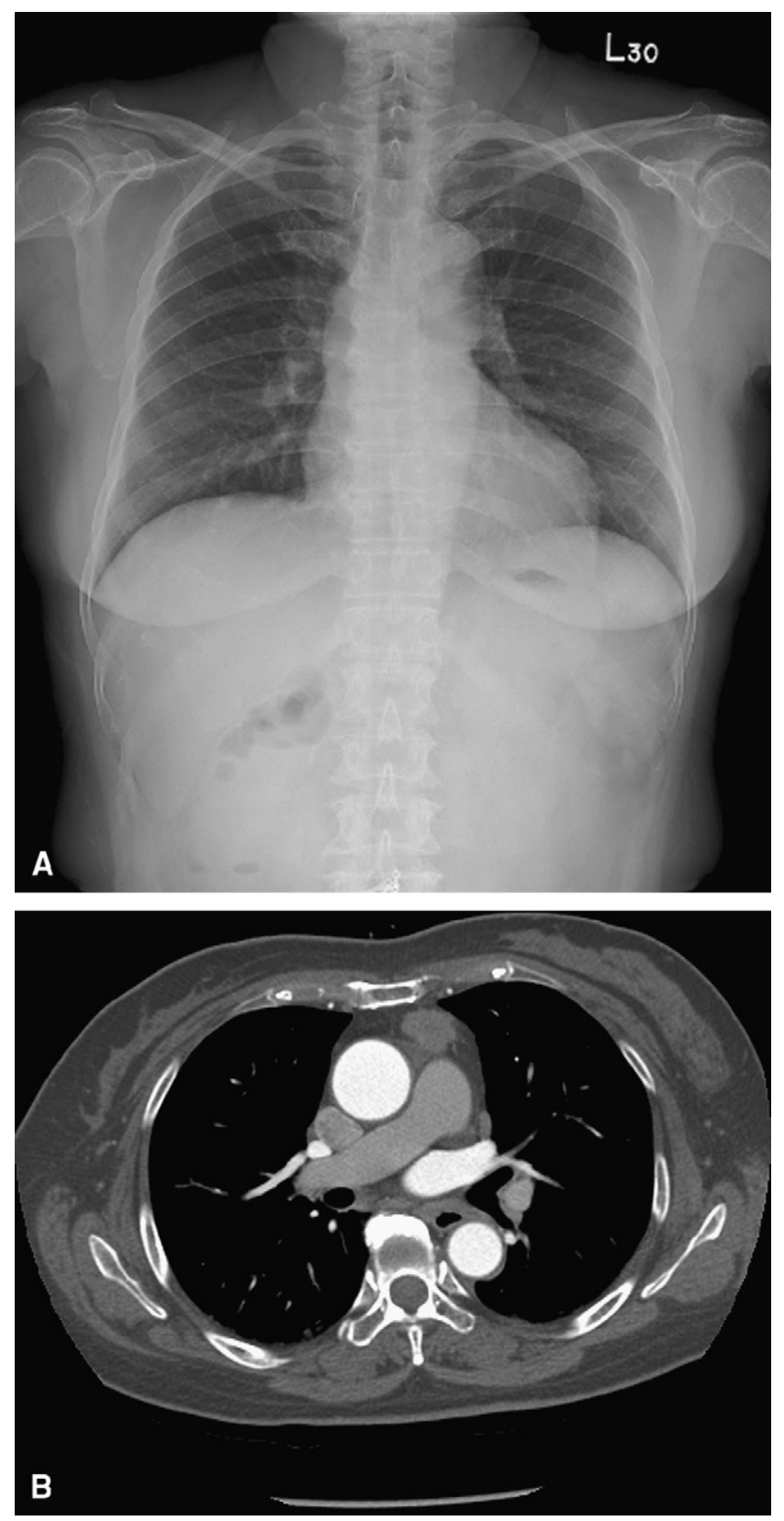

FIGURE 1. A, Chest radiograph showing no obvious mediastinal lesion. $\mathrm{B}$, Chest computed tomographic scan revealing a thymic mass in the anterior mediastinum.

symptoms and signs of Sjögren's syndrome can continue after thymectomy.,4

SIADH is a status of euvolemic hyponatremia, usually caused by malignancy, pulmonary diseases, central nervous system disorders, or drugs. It is also rarely associated with thymoma. Only 1 case of thymic carcinoma associated with SIADH has been reported. ${ }^{5}$ Water restriction is usually the choice of treatment for SIADH, but correction of the underlying disease is the key point. In our patient the serum
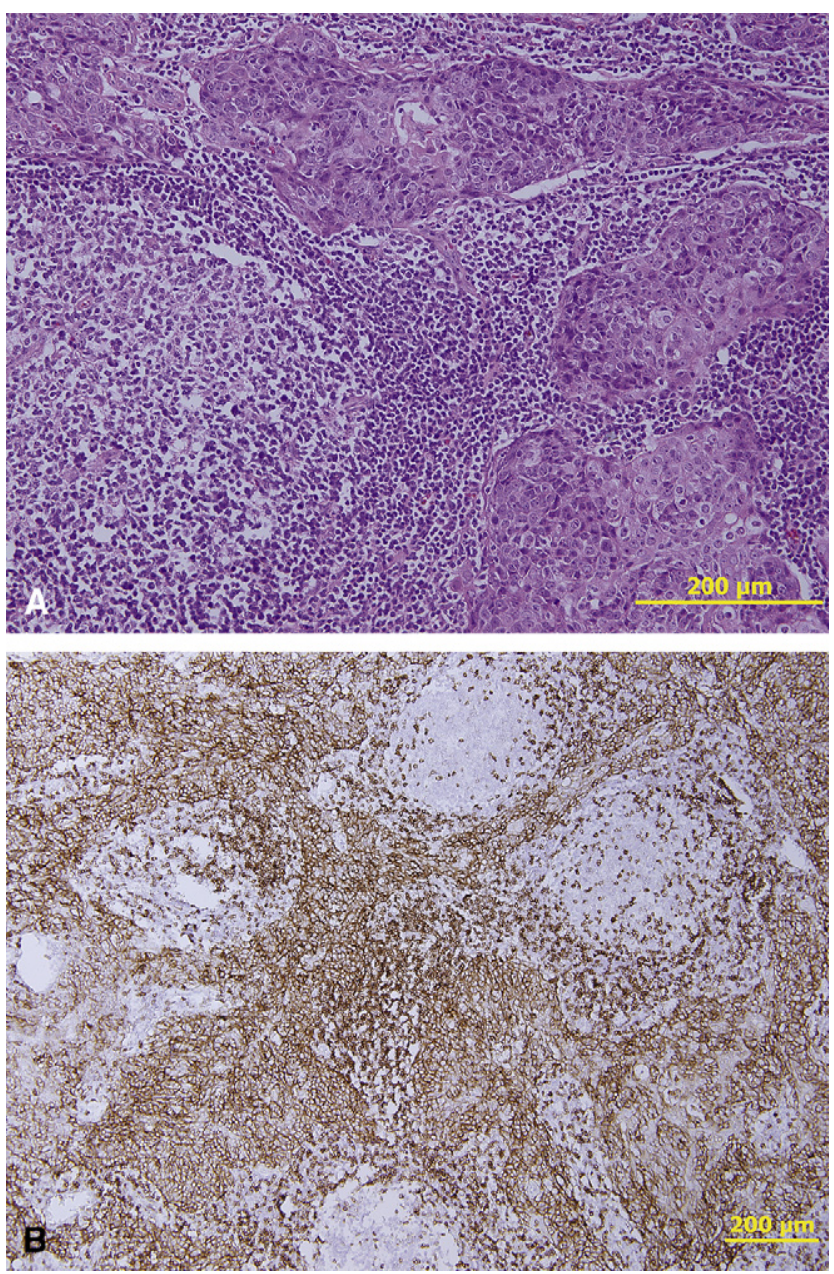

FIGURE 2. A, Histologic findings of the tumor showing malignant epithelial cell nests and prominent lymphoid follicles with germinal center formation (hematoxylin and eosin stain). B, The carcinomatous cells were immunoreactive to $\mathrm{CD} 5$, indicating thymic origin.

sodium concentration returned to the normal range within 5 months after the operation.

To our knowledge, this is the first case of thymic carcinoma associated with 2 rare parathymic syndromes: Sjögren's syndrome and SIADH.

\section{References}

1. Marx A, Ströbel P, Zettl A, Chan JKC, Müller-Hermelink HK, Harris NL, et al. Thymomas. In: Travis WD, Brambilla E, Müller-Hermelink HK, Harris CC, eds. Pathology and genetics of tumours of the lung, pleura, thymus and heart. Lyon: IARC Press; 2004:152-3.

2. Greene MA, Malias MA. Aggressive multimodality treatment of invasive thymic carcinoma. J Thorac Cardiovasc Surg. 2003;125:434-6.

3. Levy Y, Afek A, Sherer Y, Bar-Dayan Y, Shibi R, Kopolovic J, et al. Malignant thymoma associated with autoimmune diseases: a retrospective study and review of the literature. Semin Arthritis Rheum. 1998;28:73-9.

4. Matsumoto Y, Hirai S, Ohashi M, Imaizumi M. Sjögren's syndrome associated with thymoma. J Am Acad Dermatol. 1996;35:639-40.

5. Donadio AC, Dragnev KH, Schwartz GK. Thymoma associated with syndrome of inappropriate antidiuretic hormone secretion and myasthenia gravis. South Med J. 1998;91:278-9. 